\title{
Relationship Between Benzodiazepine Prescription, Aggressive Behavior, and Behavioral Disinhibition: A Case-control Study in a Swiss Prison
}

\section{Stéphanie Baggio ( $\square$ stephanie.baggio@hcuge.ch )}

Division of Prison Health, Geneva University Hospitals and University of Geneva, Geneva, Switzerland https://orcid.org/0000-0002-5347-5937

\section{Vladan Starcevic}

University of Sydney, Faculty of Medicine and Health, Sydney Medical School, Nepean Clinical School,

Discipline of Psychiatry, Sydney, NSW, Australia, vladan.starcevic@sydney.edu.au

\section{Patrick Heller}

Adult Psychiatry Division, Department of Mental Health and Psychiatry, Geneva University Hospitals, Geneva, Switzerland

\section{Karen Brändle}

Department of Forensic Psychiatry, Institute of Forensic Medicine, University of Bern, Bern, Switzerland Irina Franke

Psychiatrische Dienste Graubünden (PDGR), Chur, Switzerland

\section{Andreas Schneeberger}

Department of Psychiatry and Behavioral Sciences, Montefiore Medical Center, Albert Einstein College of Medicine, New York, USA

\section{Anna Buadze}

Department of Psychiatry, Psychotherapy and Psychosomatics, Psychiatric Hospital, University of Zurich, Zurich, Switzerland

\section{Alex Gamma}

Department of Forensic Psychiatry, Institute of Forensic Medicine, University of Bern, Bern, Switzerland

\section{Roman Schleifer}

Department of Forensic Psychiatry, Institute of Forensic Medicine, University of Bern, Bern, Switzerland

\section{Laurent Gétaz}

Division of Prison Health, Geneva University Hospitals and University of Geneva, Geneva, Switzerland

\section{Hans Wolff}

Division of Prison Health, Geneva University Hospitals and University of Geneva, Geneva, Switzerland

\section{Michael Liebrenz}

Department of Forensic Psychiatry, Institute of Forensic Medicine, University of Bern, Bern, Switzerland

\section{Research}


Keywords: benzodiazepine, drug prescription, health care, prison

DOI: https://doi.org/10.21203/rs.3.rs-53312/v1

License: (c) (1) This work is licensed under a Creative Commons Attribution 4.0 International License. Read Full License 


\section{Abstract \\ Background.}

Benzodiazepines are commonly prescribed in prisons amidst the controversies surrounding their potential role in causing behavioral disinhibition and aggressive behavior and their association with use and trafficking of illicit and addictive substances. The present study aimed to 1) ascertain the relationship between benzodiazepine prescription (including their dosage and duration of use) and aggressive behavior and behavioral disinhibition in prison, and 2) investigate whether there was an association between benzodiazepine prescription, (including their dosage and duration of use) and using and trafficking illicit and addictive substances during imprisonment.

\section{Methods.}

Data were extracted from the electronic database of an "open" Swiss prison $(n=1,379)$ over a five-year period (2010-2015). Measures included benzodiazepine prescription (yes/no), duration of benzodiazepine use and mean dosage, and punishable behaviors (physical and verbal aggression, disinhibited but not directly aggressive behaviors, property damage or theft, substance-related offenses, and rule transgression). Propensity score matching was used to assess the relationship between benzodiazepine prescription and punishable behaviors. Logistic regressions were used to test the relationship of benzodiazepine duration and dosage with punishable behaviors.

\section{Results.}

Benzodiazepine prescription (yes/no) was not significantly associated with punishable behaviors. Detained persons taking benzodiazepines were not more likely to commit offenses involving illicit or addictive substance use or trafficking, even when taking these medications in higher dosage and over a longer period of time.

\section{Conclusions.}

Our findings suggest that access to benzodiazepines in the prison setting should be subject to the same regulations as in the community and that prescribing benzodiazepines to detained persons is just as safe as prescribing these medications to those who are not detained.

\section{Introduction}

Benzodiazepines (BZD) are one of the most widely prescribed drugs in WEIRD (Western, Educated, Industrialized, Rich, and Democratic) countries [1-4]. They are mainly prescribed to treat sleep disorders, anxiety disorders, epilepsy, and withdrawal from certain substances. Their use has been widely debated. 
On one hand, BZD act quickly, are very useful in acute settings, and are generally effective. On the other, they have been associated with various adverse effects, including sedation, psychomotor and cognitive impairment, falls and fractures in the elderly, and dependence $[5,6]$. In addition, individuals with substance use disorders frequently abuse BZD, which is harmful, especially when various illicit drugs and opioids are combined with BZD [7]. In view of these problems, most treatment guidelines do not recommend BZD as first-line treatment for anxiety and related disorders and suggest that they should only be used short-term [8-10]. In contrast, several experts have recently pointed out that such recommendations are based on little empirical evidence and that these guidelines do not adequately reflect the risk-benefit ratio when using BZD $[3,4,11-14]$.

If use of BZD is controversial in the general population, the situation is even more complex in prisons, where they are commonly prescribed $[15,16]$. First, substance use disorders are more common among detained persons than in the general population [17], and smuggling and trafficking of drugs are frequent in prisons around the world [18]. Considering the likelihood of BZD abuse in the context of substance use disorders, it has been suggested that BZD should be entirely avoided or minimally prescribed in prisons $[15,19-21]$. However, this is problematic, because prisoners would be deprived of a valid therapeutic option [2, 22].

Another crucial issue associated with prescribing BZD in prisons pertains to an increased risk of behavioral disinhibition, resulting in aggressive behavior [1,23]. There is a dearth of research on this topic [24], and some studies suggest that the link between BZD use and heightened aggression may only apply to short-acting BZD [25]. Furthermore, violent crime was associated with unusually high doses of BZD [26], whereas there was no increase in impulsive behavior with therapeutic doses of BZD [27]. In a recent study, Albrecht et al [28]. concluded that high BZD doses were not sufficient to increase the risk of violence. These disparate findings make it difficult to understand the role of BZD as a treatment option in the prison setting.

In view of the aforementioned issues and controversies, the present study, conducted in a sample of Swiss detained persons, had two main aims: 1) to ascertain the relationship between BZD prescription and aggressive behavior and behavioral disinhibition in prison; we also aimed to assess the potential effects of the dosage of BZD and duration of their use on aggression and behavioral inhibition during imprisonment; and 2) to investigate whether BZD prescription was associated with using and trafficking illicit and addictive substances.

\section{Materials And Methods}

\section{Study design and participants}

This retrospective, cross-sectional study was based on the data on 1,206 persons detained in Realta prison, Kanton Grisons, Switzerland. This is an "open" prison (capacity of 120) for sentenced males who work outside the prison and have up to 36 hours of leave per week. Data for the 2010-2015 period were 
extracted from the electronic prison database on 1,379 measures (some detained persons were incarcerated multiple times). Approval for conducting the study was received from the Cantonal Research Ethics Committee of Bern (no. 2016 - 01539).

\section{Variables}

1. 1. Socio-demographics. These include age and region of origin.

2. 2. Incarceration and offense variables. We recorded the length of incarceration (based on the dates of admission and discharge) and offenses leading to imprisonment: violence-related offenses (assaults, sexual crime, other kinds of violence); property-related offenses (theft, robbery, other property offenses); substance-related offenses (violation of drug laws); and other offenses (arson, justice obstruction, manslaughter, trafficking, violation of weapon laws).

3. 3. BZD prescription. We recorded whether or not detained persons were prescribed BZD during imprisonment. For those who received BZD, duration (in days) of use and dosage (mean dosage expressed as $\mathrm{mg} /$ day and converted into diazepam mg equivalents) of BZD were collected. The list of BZD and diazepam mg equivalent conversion guidelines are provided in Supplementary Table 1.

4. 4. Other prescribed medications. We recorded whether detained persons were prescribed other psychotropic medications (i.e., antidepressants, antipsychotics, methylphenidate, mood stabilizers, or opioid agonists [including heroin used for therapeutic purposes]) and medications for any somatic (non-psychiatric) condition.

5. 5. Punishable behaviors. Data on the type and frequency of detained persons' punishable behaviors were collected. These were classified into five categories: 1) physical and verbal aggression (assaults and threats made against others), 2) disinhibited, but not directly aggressive behaviors (e.g., slamming doors, swearing), 3) property damage or theft, 4) substance-related offenses (alcohol or illicit drug use or trafficking), and 5) rule transgression (e.g., smoking when not allowed, returning from leave late). We made a binary qualification (presence/absence) for each category.

\section{Statistical analyses}

We first computed descriptive statistics for all variables. Then, we tested whether punishable behaviors were associated with BZD prescription.

In the first set of analyses, we used a propensity score matching to minimize the effect of confounding factors and make it possible to compare individuals who received BZD with those who did not receive them. This method is used to estimate the effect of a treatment when relying on observational data and to address the fact that assignment to a treatment is not random. The propensity score matching aims to mimic randomization by matching the treated and untreated groups on a set of predetermined covariables. The propensity score was estimated using a probit regression predicting BZD prescription and including the following factors: age, region of origin (Switzerland/not Switzerland), length of incarceration, type of offense, use of any other psychotropic medication, and use of any medication for somatic diseases. The balancing properties of the propensity score were satisfied. We then matched 
groups (BZD/no BZD) using nearest neighbor matching (fill Mahalanobis), allowing multiple neighbors in case of identical propensity scores. The average treatment effect on the treated (ATT) was computed for each punishable behavior used as outcome (sanctions related to physical and verbal aggression, disinhibited, but not directly aggressive behaviors, property damage or theft, substance-related offenses, and rule transgression). Crude and matched associations (before/after propensity score matching) are reported.

In the second set of analyses, we focused on detained persons who received BZD. We computed five logistic regressions, using as predictors mean dosage and duration of BZD prescription and the same outcomes as the first set of analyses. For all these models, we controlled for age, region of origin, length of incarceration, type of offenses, use of any other psychotropic medication, and use of any medication for somatic diseases.

For the propensity score analysis, we computed sensitivity analyses using other methods to match groups (covariate adjustment, inverse probability weighting, and stratification). For the second set of analyses, we performed sensitivity analyses by using the maximum BZD dosage instead of the mean dosage. We also conducted logistic regressions using mean dosage and duration of BZD use coded as zero for detained persons without BZD prescription. Finally, we controlled for the effect of short- versus long-acting BZD. In all cases, the findings were similar to those reported in the Results section.

Analyses were performed with Stata 15 (propensity score estimation: pscore with no imposition of common support, propensity matching: psmatch2 with option "ties").

\section{Results}

Descriptive statistics are reported in Table 1. The mean age of detained persons was $33.1 \pm 10.4$ years. About a third (35.4\%) came from Africa and another third (31.4\%) from Western Europe. The mean duration of incarceration was 125.1 days. 
Table 1

Descriptive statistics and bivariate analyses for socio-demographics, incarceration and offense variables, other prescribed medications, and punishable behaviors.

\section{Variables}

Whole
sample

Yes $(n=$

293)

No $(\mathrm{n}=$

1,086)

Socio-demographics

Age $^{1}$

$33.1(10.4)$

$35.4(9.8)$

$32.5(10.5)$

Region of origin ${ }^{2,3}$

Asia

Eastern Europe/Balkans

Eastern, Central \& South Africa

Latin America

Middle East

North Africa

Switzerland

Western Africa

Western Europe

Unknow/unverified

Prison variables

Length of incarceration (days) ${ }^{1}$

Type of offense ${ }^{3}$

Violence $^{2}$

Property $^{2}$

Substance ${ }^{2}$
125.1

(177.4)

$1.2(17)$

$11.6(160)$

$4.1(57)$

$1.7(23)$

6.7 (93)

$19.2(265)$

24.4 (337)

$12.0(166)$

$7.0(96)$

$12.0(165)$

$$
\text { (177.4) }
$$

13.1 (180)

12.4 (135)

38.7 (533)

54.6 (160)

34.4 (373)

19.4 (267)
1.4 (15)

12.3 (134)

4.9 (53)

1.7 (18)

7.3 (79)

18.5 (201)

21.0 (228)

14.5 (157)

7.0 (76)

11.5 (125)
$13.7(40)$
116.4

(178.1)
$15.4(45)$

157.3
$(171.6)$

$25.3(74)$
17.8 (193)

${ }^{1}$ Means and standard deviations.

2 Percentages and $n$.

${ }^{3}$ There were 165 missing values for the region of origin (12.0\%) and 40 missing values for type of offenses $(2.9 \%)$.

${ }^{4}$ Reported for participants with BZD prescription $(n=290)$. 


$\begin{array}{lll}\text { Whole } & \text { Yes }(n= & \text { No }(n= \\ \text { sample } & 293) & 1,086)\end{array}$

Other $^{2}$

60.0 (827)

$51.2(150)$

$62.3(677)$

Medical information

Benzodiazepine

Prescription $^{2}$

$21.3(293)$

Duration (no. of days) $)^{1,4}$

$91.5(7.0)$

Mean daily dosage (mg/Diazepam equivalent) $)^{1,4}$

$24.0(25.0)$

Prescription of other psychotropic medications

\begin{tabular}{|c|c|c|c|}
\hline Any $^{2}$ & $25.0(345)$ & $68.3(200)$ & $13.4(145$ \\
\hline Antidepressant $^{2}$ & $11.8 / 163)$ & $34.5(101)$ & $5.7(62)$ \\
\hline Antipsychotic ${ }^{2}$ & $15.7(217)$ & $43.3(127)$ & $8.3(90)$ \\
\hline Methylphenidate ${ }^{2}$ & $2.9(27)$ & $7.2(21)$ & $0.6(6)$ \\
\hline Mood stabilizers ${ }^{2}$ & $1.5(21)$ & $3.8(11)$ & $0.9(10)$ \\
\hline Opioid antagonist ${ }^{2}$ & $4.9(68)$ & $16.0(47)$ & $1.9(21)$ \\
\hline Other ${ }^{2}$ & $0.9(13)$ & $3.1(9)$ & $0.4(4)$ \\
\hline y medication for somatic disease ${ }^{2}$ & $32.4(447)$ & $56.3(165)$ & $26.0(282$ \\
\hline \multicolumn{4}{|l|}{ ons } \\
\hline ysical and verbal aggression ${ }^{2}$ & $5.9(81)$ & $8.5(25)$ & $5.2(56)$ \\
\hline sinhibited but not directly aggressive behavior ${ }^{2}$ & $4.7(65)$ & $7.9(23)$ & $3.9(42)$ \\
\hline operty damage or theft ${ }^{2}$ & $2.8(38)$ & $3.8(11)$ & $2.5(27)$ \\
\hline
\end{tabular}

${ }^{1}$ Means and standard deviations.

2 Percentages and $n$.

${ }^{3}$ There were 165 missing values for the region of origin (12.0\%) and 40 missing values for type of offenses $(2.9 \%)$.

${ }^{4}$ Reported for participants with BZD prescription $(n=290)$. 


\begin{tabular}{|c|c|c|c|}
\hline Variables & $\begin{array}{l}\text { Whole } \\
\text { sample }\end{array}$ & $\begin{array}{l}\text { Yes }(n= \\
293)\end{array}$ & $\begin{array}{l}\text { No }(n= \\
1,086)\end{array}$ \\
\hline Substance-related offenses ${ }^{2}$ & $11.7(161)$ & $19.1(56)$ & $9.7(105)$ \\
\hline Rule transgression ${ }^{2}$ & $23.4(323)$ & $31.7(93)$ & $21.2(230)$ \\
\hline \multicolumn{4}{|l|}{${ }^{1}$ Means and standard deviations. } \\
\hline \multicolumn{4}{|l|}{2 Percentages and $n$. } \\
\hline \multicolumn{4}{|c|}{$\begin{array}{l}3 \text { There were } 165 \text { missing values for the region of origin (12.0\%) and } 40 \text { missing values for type of } \\
\text { offenses }(2.9 \%) \text {. }\end{array}$} \\
\hline \multicolumn{4}{|c|}{${ }^{4}$ Reported for participants with BZD prescription $(n=290)$. } \\
\hline
\end{tabular}

A total of $293(21.3 \%)$ detained persons were prescribed BZD during their incarceration (mean duration of $B Z D$ use $=91.5$ days, mean dosage $=24.0 \mathrm{mg} /$ day diazepam equivalents $)$.

The most common type of punishable behavior was rule transgression (323 instances or $23.4 \%$ of the total sample), followed by substance-related offenses $(161 ; 11.7 \%)$, physical and verbal aggression (81; $5.9 \%)$, disinhibited, but not directly aggressive behaviors $(65 ; 4.7 \%)$, and property damage or theft (38; $2.8 \%)$.

In the analyses of the unmatched sample, detained persons with and without BZD prescription were significantly different in terms of the factors included in the propensity score and outcomes (left panel of Table 2). In the matched sample, there was no significant difference on any factor included in the propensity score (right panel of Table 2). Thus, BZD prescription was not significantly associated with any kind of punishable behavior. 
Table 2

Associations of factors and outcomes with BZD prescription in a sample with and without propensity score matching

\section{Sample without propensity score matching}

$\begin{array}{llllll}\text { BZD } & \text { No BZD } & p & \text { BZD } & \text { No BZD } & p \\ n=293 & n=1,086 & & n=253 & n=150 & \end{array}$

Variables included in the propensity score

\begin{tabular}{|c|c|c|c|c|c|c|}
\hline $\mathrm{Age}^{1}$ & 35.59 & 32.47 & $<.001$ & 35.59 & 35.59 & .643 \\
\hline $\begin{array}{l}\text { Region of origin (ref. } \\
\text { Switzerland) }{ }^{2}\end{array}$ & 0.43 & 0.24 & $<.001$ & 0.43 & 0.46 & .532 \\
\hline $\begin{array}{l}\text { Length of incarceration (no. of } \\
\text { days) })^{1}\end{array}$ & 158.30 & 115.37 & $<.001$ & 158.30 & 134.51 & .122 \\
\hline $\begin{array}{l}\text { Prescription of other } \\
\text { psychotropic medications }^{2}\end{array}$ & 0.67 & 0.14 & $<.001$ & 0.67 & 0.67 & .925 \\
\hline $\begin{array}{l}\text { Prescription of medication for } \\
\text { somatic disease }\end{array}$ & 0.55 & 0.25 & $<.001$ & 0.55 & 0.54 & .789 \\
\hline Offence: violence ${ }^{2}$ & 0.15 & 0.13 & .231 & 0.15 & 0.14 & .616 \\
\hline Offence: property ${ }^{2}$ & 0.53 & 0.33 & $<.001$ & 0.53 & 0.56 & .423 \\
\hline Offence: substance ${ }^{2}$ & 0.25 & 0.18 & .018 & 0.25 & 0.22 & .464 \\
\hline Offence: other ${ }^{2}$ & 0.52 & 0.62 & .002 & 0.52 & 0.53 & .722 \\
\hline
\end{tabular}

Outcomes $^{2}$

\begin{tabular}{lcccccc} 
Physical and verbal aggression & 0.08 & 0.05 & .084 & 0.08 & 0.04 & .194 \\
$\begin{array}{l}\text { Disinhibited but not directly } \\
\text { aggressive behavior }\end{array}$ & 0.17 & 0.10 & .001 & 0.17 & 0.13 & .390 \\
$\begin{array}{l}\text { Property damage or theft } \\
\text { Substance-related offenses }\end{array}$ & 0.08 & 0.04 & .001 & 0.08 & 0.07 & .576 \\
Rule transgression & 0.30 & 0.03 & .617 & 0.03 & 0.02 & .390 \\
\hline
\end{tabular}

BZD: benzodiazepine.

${ }^{1}$ Means are reported.

${ }^{2}$ Proportions are reported. 
With regards to detained persons who were prescribed BZD, the mean dosage of BZD was not associated with any kind of punishable behavior (Table 3). Duration of BZD prescription was significantly associated only with disinhibited, but not directly aggressive behaviors $(p=.011)$.

Table 3. Association between BZD dosage and duration of use and punishable behaviors $(n=290)$.

\begin{tabular}{|lllll|}
\hline DV & \multicolumn{3}{l}{ BZD mean dosage (IV1) } & \multicolumn{2}{l|}{ BZD duration (IV2) } \\
\cline { 2 - 5 } & coef. & p-value & coef. & p-value \\
\hline Physical and verbal aggression & 0.001 & .888 & 0.001 & .847 \\
\hline Disinhibited but not directly aggressive behavior & -0.021 & .110 & 0.010 & .011 \\
\hline Property damage or theft & 0.010 & .399 & -0.005 & .343 \\
Substance-related offenses & 0.003 & .611 & 0.002 & .291 \\
\hline Rule transgression & 0.008 & .171 & 0.001 & .522 \\
\hline
\end{tabular}

BZD: benzodiazepine, DV: dependent variable, IV: independent variable

Logistic models were adjusted for age, region of origin (Switzerland/not Switzerland), length of incarceration, type of offenses, prescription of any other psychotropic medication, and prescription of any medication for somatic diseases.

\section{Discussion}

The main aim of the present study was to investigate the effects of BZD prescription on aggressive behaviors and behavioral disinhibition in a Swiss prison. When controlling for potentially confounding variables, we did not find any association between BZD prescription and punishable behaviors that would reflect an increase in aggressiveness or behavioral disinhibition. This suggests that control variables might have captured a previous tendency towards aggressive behavior (reflected by the type of offenses) and psychiatric disorders associated with aggressiveness or disinhibited behaviors (reflected by the prescription of other psychotropic medications). This finding is in line with studies showing that therapeutic doses of BZD are not associated with heightened aggressive behavior [27, 28], but it is in contrast to other research that reports an association between use of BZD and aggressive behavior [1, 23]. Importantly, we also found no association between the dosage of BZD and duration of their use and almost all kinds of punishable behaviors.

The only significant result was that use of BZD for longer periods of time might increase the likelihood of engaging in disinhibited, but not directly aggressive behaviors. However, the effect size of this finding was very small: with an increase in the duration of BZD use by one day, detained persons were 1.00 times more likely to exhibit disinhibited, but not directly aggressive behaviors. 
The second aim of the study was to investigate whether BZD prescription was associated with using and trafficking illicit or addictive substances during imprisonment. We found that detained persons taking BZD were not more likely to commit offenses involving illicit or addictive substance use or trafficking. This did not change when we examined the dosage and duration of BZD use, which suggests that taking BZD even in higher dosages and over a longer period of time does not seem to lead to substance-related offenses in the prison setting. This finding has important implications because prescribing BZD in prisons is often avoided on the grounds of their presumed greater abuse potential $[19,20]$. However, abuse of BZD usually occurs in individuals with a history of substance use disorders; without this history, BZD may be administered safely even in higher dosages and for a relatively long period of time (on average, three months in our sample), with no risk that such use would inevitably lead to other substance abuse [29]. Our findings lend support to this notion in the prison setting.

Our study has also revealed other important findings about the use of BZD in the prison setting. The proportion of detained persons who were prescribed BZD (21.3\%) is by no means negligible. Moreover, when compared with detained persons who were not prescribed BZD, those using BZD were also prescribed significantly more often all other classes of psychotropic agents and medications for general medical conditions, which suggests that they had more mental health and general medical problems. A poorer mental and physical health of these detained persons indicates their greater need for adequate healthcare.

Following the principle of the equality of care, prison populations should benefit from effective and evidence-based treatments that are available in the community. In the context of our study, this means that access to BZD in the prison setting should be subject to the same regulations as in the community [2, 22]. The same applies to other psychotropic medications, as well as psychological interventions for mental disorders. It is important to acknowledge that there are very few alternatives to psychotropic medications in the prison system [30] and that treatment of many mental health issues should not only rely on medications such as BZD.

\section{Limitations}

This study has a number of limitations. First, it was based on associations and was conducted retrospectively, which precludes us from making inferences about any causal relationship. Second, punishable behaviors recorded by the prison administration were the only indicator of aggressive and disinhibited behavior, and we had no access to any information about punishable behaviors that were concealed or undetected. Future studies should be conducted prospectively and use instruments for assessing irritability, anger, behavioral disinhibition and aggressiveness. Third, our findings are based on a sample of male detained persons in a Swiss setting and it is uncertain to what extent they can be applied to female detained persons in another country. Fourth, there were no data on psychiatric diagnoses and reasons for prescribing BZD, which might have been helpful to better understand and contextualize the risk of aggressive behavior and disinhibition. Finally, prescribing any medication does 
not necessarily mean that it will be taken as prescribed, and we have no way of knowing whether detained persons were actually using BZD as prescribed.

\section{Conclusion}

Detained persons are a vulnerable population with a high burden of psychiatric and general medical morbidity; they should receive appropriate, timely and evidence-based treatment without institutional barriers to treatment access. Our findings make a significant contribution to the literature in terms of suggesting that prescribing BZD to detained persons is just as safe as prescribing these medications to those who are not detained. More specifically, we did not find support for the notions that BZD increase aggressive or disinhibited behavior in detained persons or that they increase the risk of substance abuse in this population. As with other pharmacological agents, BZD should be used carefully and cautiously in the prison setting, along with evidence-based psychological interventions.

\section{Declarations}

Ethics approval and consent to participate.Approval for conducting the study was received from the Cantonal Research Ethics Committee of Bern (no. 2016-01539).

Consent for publication. Not applicable.

Availability of data and materials. The datasets used and/or analysed during the current study are available from the corresponding author on reasonable request.

Competing interest.The authors declare that they have no competing interests.

Funding. None.

Authors contributions.SB, VS, IF, AS, AG, RS, and ML made substantial contributions to the study conception and data acquisition. SB and KB performed the statistical analyses. SB and VS drafted the manuscript. All authors made substantial contributions in the interpretation of the data and revised the manuscript critically for important intellectual content. All authors approved the final version to be published and agreed to be accountable for all aspects of the work related to its accuracy and integrity.

Acknowledgments. Not applicable.

\section{References}

1. Albrecht B, Staiger PK, Hall K, Miller P, Best D, Lubman DI. Benzodiazepine use and aggressive behaviour: a systematic review. The Australian New Zealand Journal of Psychiatry. 2014;48:1096114.

2. Liebrenz M, Boesch L, Stohler R, Caflisch C. Agonist substitution-a treatment alternative for highdose benzodiazepine-dependent patients? Addiction. 2010;105:1870-4. 
3. Starcevic V. No role for benzodiazepines in posttraumatic stress disorder? A surplus of certainty despite scarce evidence. Australasian Psychiatry: Bulletin of Royal Australian New Zealand College of Psychiatrists. 2017;25:339-41.

4. Starcevic V. The reappraisal of benzodiazepines in the treatment of anxiety and related disorders. Expert Rev Neurother. 2014;14:1275-86.

5. Kurko TaT, Saastamoinen LK, Tähkäpää S, Tuulio-Henriksson A, Taiminen T, Tiihonen J, Airaksinen MS, Hietala J. Long-term use of benzodiazepines: Definitions, prevalence and usage patterns - a systematic review of register-based studies. European Psychiatry: The Journal of the Association of European Psychiatrists. 2015;30:1037-47.

6. Lader M. Benzodiazepine harm: how can it be reduced? Br J Clin Pharmacol. 2014;77:295-301.

7. Lavie E, Fatséas M, Denis C, Auriacombe M. Benzodiazepine use among opiate-dependent subjects in buprenorphine maintenance treatment: correlates of use, abuse and dependence. Drug Alcohol Depend. 2009;99:338-44.

8. Andrews G, Bell C, Boyce P, Gale C, Lampe L, Marwat O, Rapee R, Wilkins G. Royal Australian and New Zealand College of Psychiatrists clinical practice guidelines for the treatment of panic disorder, social anxiety disorder and generalised anxiety disorder. Australian New Zealand Journal of Psychiatry. 2018;52:1109-72.

9. Baldwin DS, Anderson IM, Nutt DJ, Allgulander C, Bandelow B, den Boer JA, Christmas DM, Davies S, Fineberg N, Lidbetter N, et al. Evidence-based pharmacological treatment of anxiety disorders, posttraumatic stress disorder and obsessive-compulsive disorder: a revision of the 2005 guidelines from the British Association for Psychopharmacology. J Psychopharmacol. 2014;28:403-39.

10. Canadian Anxiety Guidelines Initiative Group on behalf of the Anxiety Disorders Association of Canada/Association Canadienne des troubles a Katzman MA, Bleau P, Blier P, Chokka P, Kjernisted K, Van Ameringen M, Canadian Anxiety Guidelines Initiative Group on behalf of the Anxiety Disorders. Association of Canada/Association Canadienne des troubles a, McGill U, Antony MM, Bouchard S, et al: Canadian clinical practice guidelines for the management of anxiety, posttraumatic stress and obsessive-compulsive disorders. BMC Psychiatry 2014, 14 Suppl 1:1.

11. Cosci F, Nardi AE, Starcevic V, Chouinard G, Balon R. Lormetazepam in oral solution: a formulation at risk of high-dose use. Internal and Emergency Medicine 2019.

12. Krystal JH, Stossel S, Krystal AD. Restricting benzodiazepines to short-term prescription. JAMA psychiatry. 2015;72:734-5.

13. Nardi AE, Cosci F, Balon R, Weintraub SJ, Freire RC, Krystal JH, Roth T, Silberman EK, Sonino N, Fava $\mathrm{GA}$, et al. The prescription of benzodiazepines for panic disorder: Time for an evidence-based educational approach. J Clin Psychopharmacol. 2018;38:283-5.

14. Rickels K, Moeller HJ. Benzodiazepines in anxiety disorders: Reassessment of usefulness and safety. The World Journal of Biological Psychiatry: The Official Journal of the World Federation of Societies of Biological Psychiatry 2018:1-5. 
15. Cabelguenne D, Picard C, Lalande L, Jonker J, Sautereau M, Meunier F, Zimmer L. Benzodiazepine dose reduction in prisoner patients: 15 years' teamwork between psychiatrists and pharmacists. J Clin Pharm Ther. 2018;43:807-12.

16. Elger BS, Goehring C, Revaz SA, Morabia A. Prescription of hypnotics and tranquilisers at the Geneva prison's outpatient service in comparison to an urban outpatient medical service. SozialPraventivmedizin. 2002;47:39-43.

17. Fazel S, Yoon IA, Hayes AJ. Substance use disorders in prisoners: an updated systematic review and meta-regression analysis in recently incarcerated men and women. Addiction. 2017;112:1725-39.

18. Borrey D, Meyer E, Duchateau L, Lambert W, Van Peteghem C, De Leenheer AP. Longitudinal study on the prevalence of benzodiazepine (mis) use in a prison: Importance of the analytical strategy. Addiction. 2003;98:1427-32.

19. McKee J, Penn JV, Koranek A. Psychoactive medication misadventuring in correctional health care. Journal of Correctional Health Care. 2014;20:249-60.

20. Pilkinton PD, Pilkinton JC. Prescribing in prison: Minimizing psychotropic drug diversion in correctional practice. Journal of Correctional Health Care. 2014;20:95-104.

21. Reeves R. Guideline, education, and peer comparison to reduce prescriptions of benzodiazepines and low-dose Quetiapine in prison. Journal of Correctional Health Care. 2012;18:45-52.

22. Elger BS. Prisoners' insomnia: to treat or not to treat? Medical decision-making in places of detention. Med Sci Law. 2008;48:307-16.

23. Lekka NP, Paschalis C, Papadourakis A, Beratis S. Characteristics of inmates receiving prescribed benzodiazepines in a high-security greek prison. Compr Psychiatry. 2003;44:409-14.

24. Watson TM. Prisoners' access to psychoactive medications: The need for research and improved policy. The International Journal on Drug Policy. 2016;29:98-9.

25. Liebrenz M, Schneider M, Buadze A, Gehring M-T, Dube A, Caflisch C. High-dose benzodiazepine users' perceptions and experiences of anterograde amnesia. The Journal of the American Academy of Psychiatry the Law. 2016;44:328-37.

26. Lundholm L, Haggård U, Möller J, Hallqvist J, Thiblin I. The triggering effect of alcohol and illicit drugs on violent crime in a remand prison population: A case crossover study. Drug Alcohol Depend. 2013;129:110-5.

27. Reynolds B, Richards JB, Dassinger M, de Wit H. Therapeutic doses of diazepam do not alter impulsive behavior in humans. Pharmacology Biochemistry Behavior. 2004;79:17-24.

28. Albrecht B, Staiger PK, Best D, Hall K, Nielsen S, Lubman DI, Miller P. Benzodiazepine use of community-based violent offenders: a preliminary investigation. Journal of Substance Use. 2017;22:295-303.

29. O'Brien CP. Benzodiazepine use, abuse, and dependence. The Journal of Clinical Psychiatry. 2005;66(Suppl 2):28-33. 
30. Bartlett A, Dholakia N, England R, Hales H, Horn Ev, McGeorge T, Moss B, Ovaisi S, Tukmachi E, Patel $\mathrm{S}$. Prison prescribing practice: practitioners' perspectives on why prison is different. Int $\mathrm{J}$ Clin Pract. 2014;68:413-7.

\section{Supplementary Files}

This is a list of supplementary files associated with this preprint. Click to download.

- SupplementaryTable1.docx 